\title{
Article \\ Naturalistic Stress Hormone Levels Drive Cumulative Epigenomic Changes along the Cellular Lifespan
}

\author{
Anthony S. Zannas $1,2,3,+\mathbb{D}$ \\ 1 Department of Psychiatry, University of North Carolina, Chapel Hill, NC 27514, USA; \\ anthony_zannas@med.unc.edu; Tel.: +1-(919)-962-4918 \\ 2 Department of Genetics, University of North Carolina, Chapel Hill, NC 27514, USA \\ 3 Carolina Stress Initiative, University of North Carolina School of Medicine, Chapel Hill, NC 27514, USA \\ † 438 Taylor Hall, 109 Mason Farm Road, Chapel Hill, NC 27599, USA.
}

check for updates

Citation: Zannas, A.S. Naturalistic Stress Hormone Levels Drive Cumulative Epigenomic Changes along the Cellular Lifespan. Int. J. Mol. Sci. 2021, 22, 8778. https:// doi.org/10.3390/ijms22168778

Academic Editor: Antonio Simone Laganà

Received: 29 July 2021

Accepted: 14 August 2021

Published: 16 August 2021

Publisher's Note: MDPI stays neutral with regard to jurisdictional claims in published maps and institutional affiliations.

Copyright: (C) 2021 by the author. Licensee MDPI, Basel, Switzerland. This article is an open access article distributed under the terms and conditions of the Creative Commons Attribution (CC BY) license (https:/ / creativecommons.org/licenses/by/ $4.0 /)$.

\begin{abstract}
Environmental stress is ubiquitous in modern societies and can exert a profound and cumulative impact on cell function and health phenotypes. This impact is thought to be in large part mediated by the action of glucocorticoid stress hormones, primarily cortisol in humans. While the underlying molecular mechanisms are unclear, epigenetics-the chemical changes that regulate genomic function without altering the genetic code-has emerged as a key link between environmental exposures and phenotypic outcomes. The present study assessed genome-wide DNA (CpG) methylation, one of the key epigenetic mechanisms, at three timepoints during prolonged (51-day) exposure of cultured human fibroblasts to naturalistic cortisol levels, which can be reached in human tissues during in vivo stress. The findings support a spatiotemporal model of profound and widespread stress hormone-driven methylomic changes that emerge at selected CpG sites, are more likely to spread to nearby located CpGs, and quantitatively accrue at open sea, glucocorticoid receptor binding, and chromatin-accessible sites. Taken together, these findings provide novel insights into how prolonged stress may impact the epigenome, with potentially important implications for stress-related phenotypes.
\end{abstract}

Keywords: cortisol; DNA methylation; environmental stress; epigenetics; fibroblasts; glucocorticoids

\section{Introduction}

Environmental stress is ubiquitous in modern societies and can exert profound impact on cell and body function [1,2]. This impact can accumulate throughout the human life and contribute to a host of disease states together responsible for $70 \%$ of all deaths [3]. Although the underlying mechanisms are unclear, epigenetics - the chemical changes that regulate genomic function without altering the genetic code-has emerged as a key link between the environment and health [4-6]. Studying the epigenetic sequelae of stress can thus yield fundamental insights into determinants of health and disease. In particular, DNA methylation at cytosines followed by guanine residues (CpG) is one of the most widely studied epigenetic modifications in humans and has been proposed as a key mechanism mediating the impact of stress on cell function and phenotypic outcomes [4,6-9].

While stress can result from heterogeneous physical, mental, and social stimuli, all stressors share an ability to trigger conserved neuroendocrine responses that culminate in systemic secretion of glucocorticoid stress hormones, primarily cortisol in humans [10]. Systemic glucocorticoids, in turn, can influence genomic function in essentially every human cell by activating the glucocorticoid receptor (GR), a ligand-regulated transcription factor [11]. Glucocorticoid exposure and GR activation can induce not only acute changes in gene transcription but also lasting epigenetic changes, most notably in DNA methylation [12-19]. Building on sparse existing evidence, we previously further hypothesized that prolonged or repeated exposure to stress and glucocorticoids can induce cumulative epigenetic changes at susceptible genomic sites $[6,11]$. 
To address this hypothesis and spatiotemporally characterize the cumulative epigenomic effects of prolonged stress, the present study employs a well-established line of cells (IMR-90 fibroblasts). Fibroblasts are particularly suitable in this setting, because they have a finite replicative potential (cellular lifespan) but can also be treated in culture for a long period of time ( $\geq 2$ months) [20]. While the majority of prior studies have used either large concentrations of cortisol or synthetic (and much more potent) glucocorticoids [14,17-19,21-25], the present study models naturalistic stress hormone exposure using cortisol at a concentration of $100 \mathrm{nM}$, which can be reached in human tissues during in vivo stress [26-30]. Taken together, the findings show that prolonged exposure to naturalistic cortisol levels induces profound and widespread methylomic changes that emerge at selected CpG sites, are more likely to spread to nearby located CpGs, and quantitatively accrue at open sea, GR binding, and chromatin-accessible sites.

\section{Results}

2.1. Prolonged Exposure to Naturalistic Stress Hormone Levels Induces Widespread and Cumulative Methylomic Changes

IMR-90 cells underwent prolonged exposure to either vehicle or $100 \mathrm{nM}$ cortisol (as indicated below), and genome-wide DNA methylation was measured with the Illumina Infinium HumanMethylationEPIC BeadChip at three time points (cell passages): 0 days ("early"), to determine baseline methylation right before treatment onset; 24 days ("mid$\left.\mathrm{dle}^{\prime \prime}\right)$, an intermediate timepoint to assess potential cumulative epigenomic effects; and 51 days ("late"), the latest time point following treatment completion. Principle component analysis (PCA) of genome-wide DNA methylation data (total 709,065 CpG sites after quality control) indicated that the effects of prolonged exposure to cortisol accumulate and shape distinct epigenomic landscapes through transition from early to middle and late passage (Figure 1A). To further characterize the spatiotemporal distribution of cortisol-induced methylomic changes, linear regression models tested if treatment condition (cortisol vs. vehicle) and duration (up to 51 days) interact to influence methylation at each EPIC arraycovered CpG site. This analysis identified a total of $129,596 \mathrm{CpGs}$ exhibiting statistically significant condition-duration interaction as well as significant DNA methylation differences between cortisol and vehicle groups at either middle or late passage (FDR-adjusted $p<0.05)$. Among these, significant cortisol-induced methylation changes already emerged for $6909 \mathrm{CpG}$ sites at middle passage (3660 hyper- and 3249 hypo-methylated), whereas changes became significant for 128,507 CpGs at late passage (57,129 hyper- and 71,378 hypomethylated) (Figure 1B). For the $5820 \mathrm{CpGs}$ with significant methylation changes at both timepoints, the magnitude of cortisol-induced changes was much smaller for middle passage (hypermethylation mean $5.0 \%$, SD $4.0 \%$, max 26.9\%; hypomethylation mean $-5.0 \%$, SD $5.9 \%$, max $-47.3 \%$ ) as compared to late passage (hypermethylation mean $12.5 \%$, SD $5.9 \%$, max $45.0 \%$; hypomethylation mean $-12.7 \%$, SD $6.3 \%$, max $-58.0 \%$ ) (Figure 1C). These observations suggest that prolonged exposure to naturalistic stress hormone levels affects a gradually (and seemingly exponentially) increasing number of CpG sites, while also driving potentially cumulative methylation changes at some of the affected CpGs. 
A

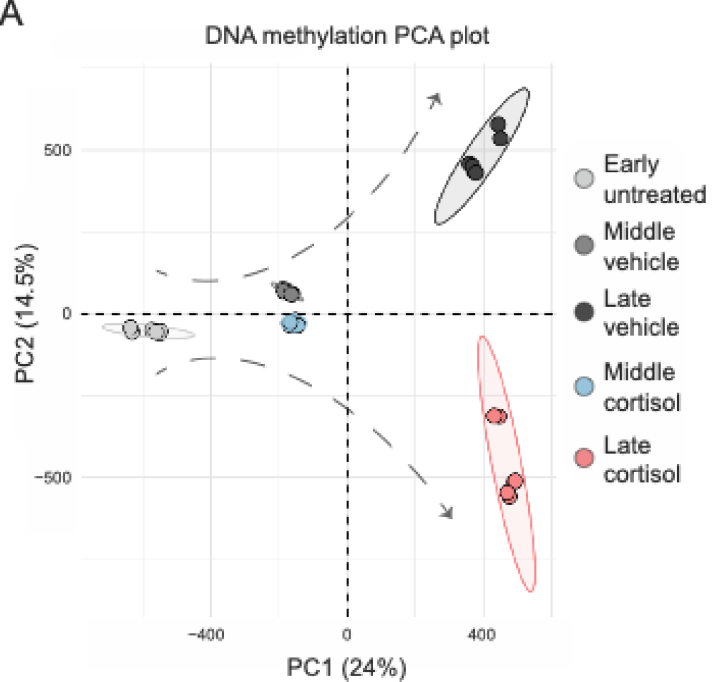

B

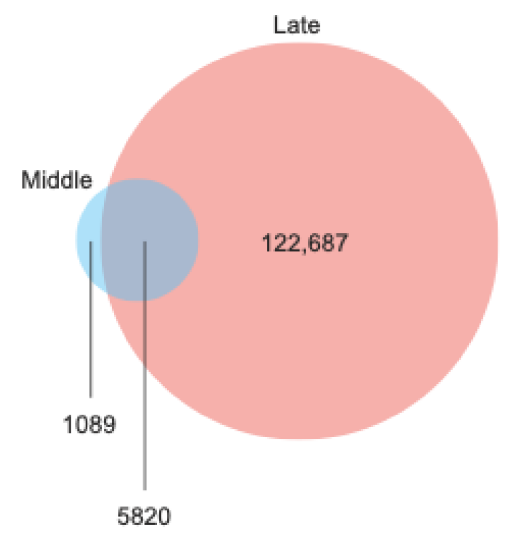

C

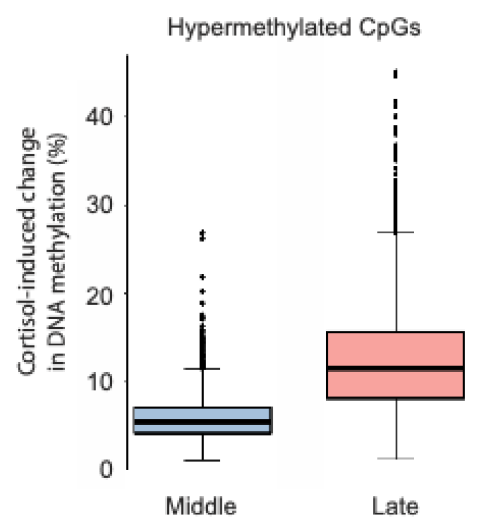

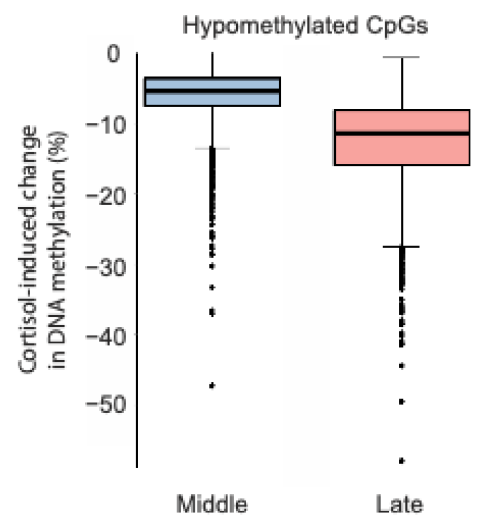

Figure 1. Prolonged cortisol exposure induces widespread and cumulative DNA methylation changes. (A). Principal component analysis (PCA) of Illumina EPIC array data showing the progression of cortisol-induced methylomic changes along the cellular lifespan. (B). Venn diagram depicting the number of $\mathrm{CPG}$ sites with significant treatment condition-duration interaction and methylation differences between cortisol and vehicle groups at middle or late passage. (C). Boxplots comparing the magnitude of cortisol-induced methylation changes (hyper- or hypo-methylation) at middle and late passage. Each datapoint represents a significantly changing $\mathrm{CpG}$ and methylation changes.

\subsection{Stress Hormone-Driven DNA Methylation Changes Are more Likely to Emerge near already Affected $C p G$ Sites}

The observation that prolonged stress hormone exposure affects an exponentially increasing number of $\mathrm{CpG}$ sites warrants further examination. Because DNA methylation patterns, once established, can influence local chromatin accessibility $[14,17,19,31]$, it can be hypothesized that the initial methylation changes induced by cortisol at susceptible CpG sites could facilitate subsequent additional changes at proximally located CpGs. To address this "epigenetic seeding and spreading hypothesis", analyses examined the likelihood of additional cortisol-induced methylation changes to emerge at late passage ("spreading") at CpG sites located within varying windows $(1,10$, or $100 \mathrm{~kb})$ from the closest $\mathrm{CpG}$ affected already at middle passage ("seeding"). These analyses used all EPIC array-covered CpG sites as a background (excluding the ones identified as seeding sites) and showed that epigenetic spreading is more likely to occur at $\mathrm{CpGs}$ located near seeding sites for all selected windows (all $p$-values $<2.2 \times 10^{-16}$; Figure 2A). Moreover, the magnitude of methylation changes at spreading CpGs inversely correlated, albeit weakly, with the distance from the closest seeding CpG (Figure 2B; Spearman $\rho=-0.08, p=5.7 \times 10^{-7}$ for 
the 1-kb window). These results suggest that stress hormone-driven methylation changes are more likely to emerge and show a greater magnitude of effect at genomic sites located near already affected sites.

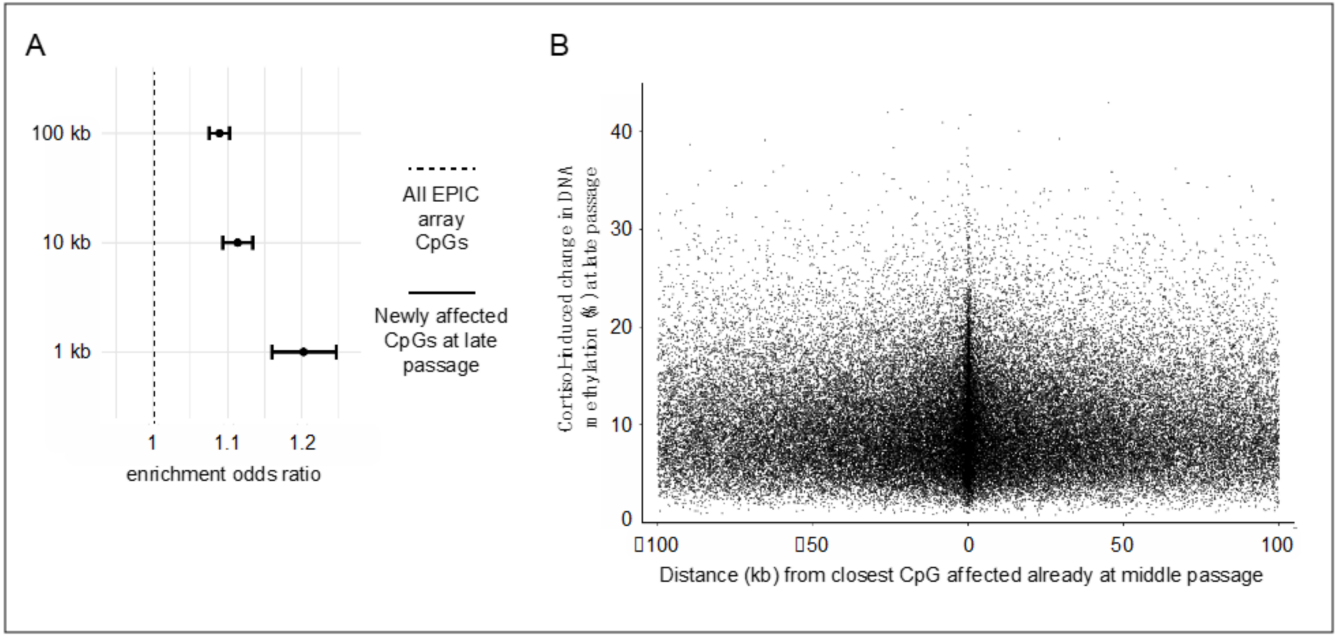

Figure 2. Cortisol-induced methylation changes are more likely to emerge and show greater magnitude of effect at genomic sites located near already affected sites. (A). Enrichment analyses of cortisol-induced methylation changes newly emerging at late passage at $\mathrm{CpG}$ sites located within varying windows $(1,10$, or $100 \mathrm{~kb})$ from the closest $\mathrm{CpG}$ affected already at middle passage. Error bars show odds ratios and 95\% confidence intervals, which were calculated with Fisher's exact test. (B). Scatterplot depicting the relation between absolute cortisol-induced DNA methylation changes at newly affected CpGs at late passage and distance from the closest CpG affected already at middle passage. Each datapoint depicts a significantly changing CpG.

2.3. Stress Hormone-Driven DNA Methylation Changes Quantitatively Accrue at Open Sea, GR Binding, and Chromatin-Accessible Sites

Subsequent analyses aimed to better characterize $\mathrm{CpG}$ sites with potential cumulative cortisol-induced changes in DNA methylation. Among the $5820 \mathrm{CpG}$ sites undergoing cortisol-induced methylation changes at both middle and late passage (Figure 1B,C), a total of 4646 CpGs exhibited a consistent direction of change (hyper- or hypo-methylation) at both timepoints and greater cortisol-induced changes at late as compared to middle passage, i.e., cumulative cortisol-induced DNA methylation changes. These sites are hereinafter denoted by "stress-accruing CpGs" and described in more detail in Supplementary Table S1. As compared to all EPIC array-covered CpG sites, the stress-accruing CpGs were more likely to be annotated at open sea genomic regions as opposed to CpG islands (OR 4.7, 95\% CI 4.1 to 5.4) and to be localized within GR ChIP-seq peaks previously identified in IMR-90 cells [32] (OR 2.9, 95\% CI 2.6 to 3.3) and accessible chromatin regions defined by ENCODEderived DNase hypersensitivity sites (OR 1.5, 95\% CI 1.4 to 1.6 ) (all $p$-values $<2.2 \times 10^{-16}$; Figure $3 \mathrm{~A}, \mathrm{~B})$. Taken together, these findings support local genomic context as an important determinant of cortisol-induced methylation changes, which tend to quantitatively accrue at open sea, GR binding, and chromatin-accessible sites. 


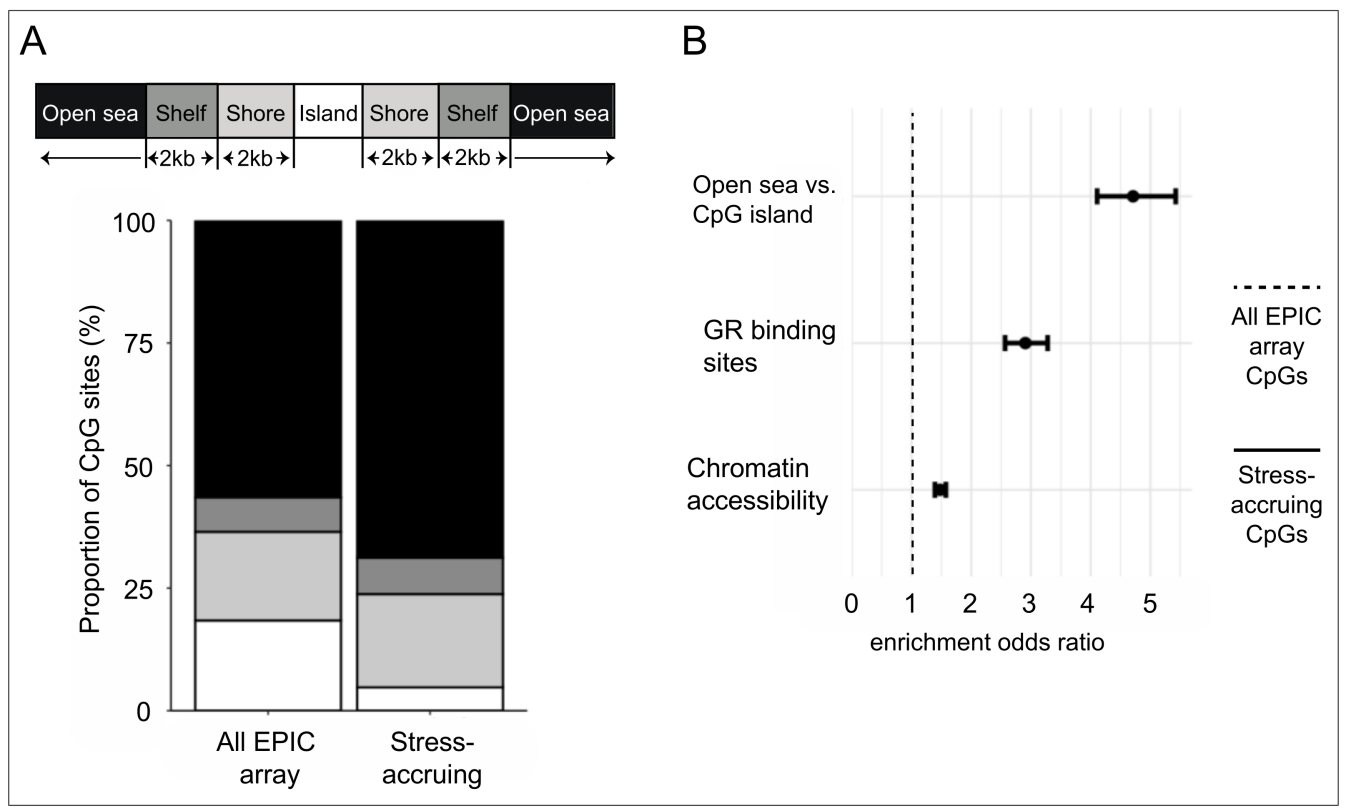

Figure 3. Cortisol-induced DNA methylation changes accrue at open sea, GR binding, and chromatinaccessible sites. (A). Stacked bar plot comparing the genomic region annotation of all EPIC arraycovered and the stress-accruing CpG sites. (B). Enrichment analyses comparing the functional annotation of all EPIC array-covered CpG sites with that of the stress-accruing CpGs. Error bars show odds ratios and 95\% confidence intervals, which were calculated with Fisher's exact test.

\section{Discussion}

Environmental stress has been proposed to impact cell function and phenotypic outcomes via DNA methylation changes [4,6-9], and prolonged stress exposure has been further hypothesized to induce cumulative methylation changes at susceptible genomic sites [6,11]. Building on this hypothesis, the present study shows that prolonged glucocorticoid stress hormone (cortisol) exposure in cell culture induces profound and widespread methylomic changes that emerge at selected $\mathrm{CpG}$ sites, are more likely to spread to nearby located CpGs, and quantitatively accrue at open sea, GR-susceptible, and chromatinaccessible sites.

By assessing multiple timepoints (early, middle, late passage) during prolonged (51-day) exposure to naturalistic cortisol levels, the present study identified a spatiotemporal pattern of cortisol-induced methylomic changes that appear to affect an exponentially increasing number of $\mathrm{CpG}$ sites with time and are more likely to emerge near already affected sites. These results extend prior work showing that DNA methylation changes gradually emerge across juxtaposed CpGs during a shorter (4-day) treatment with the synthetic (and much more potent) glucocorticoid dexamethasone [14], while also suggesting that widespread epigenetic changes become established over longer timescales during exposure to naturalistic cortisol levels. Although no studies have compared the methylomewide effects of cortisol and dexamethasone, differences in the time-course and strength of establishment are plausible given that synthetic glucocorticoids have transcriptional effects markedly different from those of naturally occurring glucocorticoids [33]. Such differences highlight the importance of considering compound type and concentration when modeling stress in cell culture. Taken together, these results also build on prior work to support a "stress-driven epigenomic seeding and spreading" hypothesis, which could be explained by DNA methylation-dependent gating of local chromatin accessibility and transcription factor binding $[14,17,19,31]$. This intriguing hypothesis remains to be further tested and characterized by studies that include additional timepoints and more comprehensive epigenomic profiling. 
Another key observation is that cortisol-induced methylation changes can quantitatively accrue over time at selected CpG sites. Such CpGs could serve as epigenetic signatures and potential biomarkers of prolonged glucocorticoid and stress exposure. Supporting this possibility, the extent of methylation changes at selected CpGs of the glucocorticoid-responsive FKBP5 gene has been shown to correlate with the total burden of glucocorticoid exposure in mice [34]. Notably, the stress-accruing CpGs show strong enrichment for localization at open sea, GR binding, and chromatin-accessible sites. These localization findings are in line with previous work in both humans and cells. Specifically, CpG sites located at open sea regions are more frequently associated with environmental stress, such as childhood maltreatment and natural disasters [35,36], and CpGs co-localizing with GR binding sites are more likely to show methylation changes as a result of both cumulative lifetime stress and dexamethasone administration [16]. Furthermore, the methylation status at individual CPG sites has been shown to correlate with their chromatin accessibility at the single-cell level [37]. Together these findings suggest that local genomic context is an important determinant of the methylomic changes induced by cortisol and may thus play crucial roles in shaping the epigenomic effects of stress over time.

The findings of the present study should be viewed within the context of its limitations. The EPIC array interrogates most human genes ( $\sim 99 \%$ of all known genes), yet only sparsely covers the human methylome ( $3 \%$ of all CpG sites). Thus, it is possible that stressdriven methylation changes at $\mathrm{CpG}$ sites not covered by the array could follow principles considerably different from those observed here, and this possibility can only be addressed by more comprehensive profiling methods, such as whole-genome bisulfite sequencing. Moreover, this study characterized the methylomic effects of prolonged cortisol exposure but did not distinguish between effects mediated by physical interaction of the GR with genomic sites and other effects of glucocorticoid signaling. For example, it is possible that many epigenomic effects do not require GR binding to the genome but can occur due to glucocorticoid effects on fundamental cell processes, such as proliferation and metabolism. Cell proliferation is itself associated with methylation changes [38], and future studies may determine the extent to which the present findings generalize to relevant nonreplicating cells, such as neurons. Lastly, the present study included a considerable number of biological replicates to increase the power for detecting cortisol-induced methylation changes but only assessed a limited number of time snapshots. Assessing additional timepoints will provide a more nuanced understanding of how stress hormone-driven methylomic changes become established along the cellular lifespan.

In conclusion, the present study shows that prolonged exposure to naturalistic stress hormone levels induces profound and widespread methylomic changes that emerge, spread, and accrue over time in a site-dependent manner. Follow-up cell culture and in vivo studies that employ more comprehensive epigenomic profiling, additional timepoints of assessment, and targeted experimental manipulations may provide deeper insights into how prolonged stress impacts the epigenome to shape phenotypic outcomes.

\section{Materials and Methods}

\subsection{Cell Culture and Treatments}

Human IMR-90 (female fetal lung fibroblast) cells were obtained from the Coriell Institute Cell Repository and were maintained in no-phenol-red Dulbecco's Modified Eagle Medium (DMEM) supplemented with 15\% fetal bovine serum, high glucose, sodium pyruvate, l-glutamine, non-essential amino acids, and antibiotic/antimycotic. Cells were grown in a humidified incubator at $37^{\circ} \mathrm{C}$ and $5 \% \mathrm{CO}_{2}$. All cultures were seeded at a cell density of 10,000 cells $/ \mathrm{cm}^{2}$ and allowed to proliferate for four to five days or until the cells reached $90 \%$ confluency. Cortisol was diluted in a very low final amount of DMSO $(0.0001 \%)$ and continuously added to cultures for the indicated duration of time at a final concentration of $100 \mathrm{nM}$. The same final DMSO concentration was used as a vehicle control. Both compounds were purchased from Sigma-Aldrich (St. Louis, MO, USA) and were replaced in fresh media simultaneously for both groups every two to three days throughout 
treatment. IMR-90 cells were then collected while still replicating at early, middle, and late passage after receiving 0,24 , or 51 days, respectively, of continuous treatment with cortisol or vehicle for downstream DNA extraction and methylation measurements. Each treatment condition included six biological replicates.

\subsection{DNA Methylation Measurements}

DNA was extracted using the Genfind V3 DNA extraction kit (Beckman Coulter, Brea, CA, USA) according to manufacturer instructions. DNA concentration and purity were determined using the Take3 microplate spectrophotometer (BioTek Instruments, Winooski, VT, USA). Extracted DNA was bisulfite converted using EZ-96 DNA Methylation Kit (Zymo Research, Irvine, CA, USA), and genome-wide DNA methylation was measured with the Illumina Infinium HumanMethylationEPIC BeadChip (EPIC), which assays DNA methylation at $>850,000 \mathrm{CpG}$ sites [39]. According to standard quality control procedures, the following probes were removed: (i) previously identified cross-reactive and polymorphic probes [40]; (ii) CpG probes with less than 3 beads or with a detection $p$-value over $1 \%$ in at least $1 \%$ of the samples assayed; (iii) $C p G$ probes mapping to the $Y$ chromosome (given that IMR-90 cells originate from a female fetus); and (iv) probes containing SNPs with a minor allele frequency $>1 \%$ located within 10 bases of the CpG. Following this standardized procedure, a total of 709,065 CpG was included in subsequent analyses. Raw signal intensities were normalized with subset quantile normalization available in the minfi package [41]. Normalized intensity values were then converted into beta values, which were used in all analyses. To adjust for technical batch effects, EPIC arrays were run after randomizing DNA samples from different cell passages and treatment conditions across plate, chip, row, and column. The lack of significant batch effects in the data was confirmed with iterative covariate inspection after principle component analysis, as implemented in the RaMWAS pipeline $[42,43]$.

\subsection{Statistical Analyses}

To identify CpG sites undergoing methylation changes during prolonged cortisol exposure, linear regression models tested the effect of the interaction between treatment condition (cortisol vs. vehicle) and duration (early, middle, and late passage) on methylation levels at each EPIC array-covered CpG. Student's $t$-test assessed methylation differences between cortisol and vehicle groups at middle and late passage. The Spearman method was used to test the correlation between the cortisol-induced methylation change at each spreading CpG and the distance from the closest seeding CpG. To assess the localization of CpGs within GR binding sites, analyses used online available GR ChIP-seq peaks previously identified in IMR-90 cells [32]. Localization for genomic region (open sea, shelf, shore, CpG island) and ENCODE-derived DNase hypersensitivity sites was performed using the EPIC array annotation (manifest file) derived through the minfi package [41]. Enrichment analyses were performed using Fisher's exact test with the indicated EPIC array CpGs as background. All $p$-values were 2-tailed, correction for multiple testing was done with the false discovery rate method, and results were considered statistically significant based on an adjusted threshold of $\alpha=0.05$. All statistical analyses were conducted in $\mathrm{R}$ version 3.6.3.

Supplementary Materials: Supplementary materials can be found at https:/ /www.mdpi.com/ article/10.3390/ijms22168778/s1.

Author Contributions: Conceptualization, design, formal analysis, original draft preparation, and writing was conducted by A.S.Z. The author has read and agreed to the published version of the manuscript.

Funding: This research received no external funding.

Institutional Review Board Statement: Not applicable.

Informed Consent Statement: Not applicable.

Data Availability Statement: Not applicable. 
Acknowledgments: The following cell line was obtained from the NIGMS Human Genetic Cell Repository at the Coriell Institute for Medical Research: I90-83. The author would like to acknowledge Oksana Kosyk for performing cell culture experiments.

Conflicts of Interest: The author declares no conflict of interest.

\section{References}

1. Hong, J.Y.; Lim, J.; Carvalho, F.; Cho, J.Y.; Vaidyanathan, B.; Yu, S.; Annicelli, C.; Ip, W.K.E.; Medzhitov, R. Long-Term Programming of CD8 T Cell Immunity by Perinatal Exposure to Glucocorticoids. Cell 2020, 180, 847-861.e815. [CrossRef] [PubMed]

2. Yang, Y.H.; Istomine, R.; Alvarez, F.; Al-Aubodah, T.A.; Shi, X.Q.; Takano, T.; Thornton, A.M.; Shevach, E.M.; Zhang, J.; Piccirillo, C.A. Salt Sensing by Serum/Glucocorticoid-Regulated Kinase 1 Promotes Th17-like Inflammatory Adaptation of Foxp3(+) Regulatory T Cells. Cell Rep. 2020, 30, 1515-1529.e1514. [CrossRef]

3. World Health Organization. Noncommunicable Diseases Progress Monitor; World Health Organization: Geneva, Switzerland, 2017.

4. Cavalli, G.; Heard, E. Advances in epigenetics link genetics to the environment and disease. Nature 2019, 571, 489-499. [CrossRef]

5. National Library of Medicine, Genetics Home Reference. What Is Epigenetics? Available online: https://ghr.nlm.nih.gov/ primer/howgeneswork/epigenome (accessed on 15 July 2021).

6. Zannas, A.S. Decoding the life story of our epigenome. Epigenomics 2019, 11, 1233-1236. [CrossRef] [PubMed]

7. Lam, L.L.; Emberly, E.; Fraser, H.B.; Neumann, S.M.; Chen, E.; Miller, G.E.; Kobor, M.S. Factors underlying variable DNA methylation in a human community cohort. Proc. Natl. Acad. Sci. USA 2012, 109 (Suppl. S2), 17253-17260. [CrossRef]

8. Weaver, I.C.; Cervoni, N.; Champagne, F.A.; D'Alessio, A.C.; Sharma, S.; Seckl, J.R.; Dymov, S.; Szyf, M.; Meaney, M.J. Epigenetic programming by maternal behavior. Nat. Neurosci. 2004, 7, 847-854. [CrossRef] [PubMed]

9. Yong, W.S.; Hsu, F.M.; Chen, P.Y. Profiling genome-wide DNA methylation. Epigenetics Chromatin 2016, 9, 26. [CrossRef]

10. Chrousos, G.P.; Gold, P.W. The concepts of stress and stress system disorders. Overview of physical and behavioral homeostasis. JAMA 1992, 267, 1244-1252. [CrossRef]

11. Zannas, A.S.; Chrousos, G.P. Epigenetic programming by stress and glucocorticoids along the human lifespan. Mol. Psychiatry 2017, 22, 640-646. [CrossRef]

12. Kress, C.; Thomassin, H.; Grange, T. Active cytosine demethylation triggered by a nuclear receptor involves DNA strand breaks. Proc. Natl. Acad. Sci. USA 2006, 103, 11112-11117. [CrossRef] [PubMed]

13. Seifuddin, F.; Wand, G.; Cox, O.; Pirooznia, M.; Moody, L.; Yang, X.; Tai, J.; Boersma, G.; Tamashiro, K.; Zandi, P.; et al. Genome-wide Methyl-Seq analysis of blood-brain targets of glucocorticoid exposure. Epigenetics 2017, 12, 637-652. [CrossRef]

14. Thomassin, H.; Flavin, M.; Espinas, M.L.; Grange, T. Glucocorticoid-induced DNA demethylation and gene memory during development. EMBO J. 2001, 20, 1974-1983. [CrossRef] [PubMed]

15. Wiechmann, T.; Röh, S.; Sauer, S.; Czamara, D.; Arloth, J.; Ködel, M.; Beintner, M.; Knop, L.; Menke, A.; Binder, E.B.; et al. Identification of dynamic glucocorticoid-induced methylation changes at the FKBP5 locus. Clin. Epigenetics 2019, 11, 83. [CrossRef] [PubMed]

16. Zannas, A.S.; Arloth, J.; Carrillo-Roa, T.; Iurato, S.; Roh, S.; Ressler, K.J.; Nemeroff, C.B.; Smith, A.K.; Bradley, B.; Heim, C.; et al. Lifetime stress accelerates epigenetic aging in an urban, African American cohort: Relevance of glucocorticoid signaling. Genome Biol. 2015, 16, 266. [CrossRef]

17. Zannas, A.S.; Jia, M.; Hafner, K.; Baumert, J.; Wiechmann, T.; Pape, J.C.; Arloth, J.; Kodel, M.; Martinelli, S.; Roitman, M.; et al. Epigenetic upregulation of FKBP5 by aging and stress contributes to NF-kappaB-driven inflammation and cardiovascular risk. Proc. Natl. Acad. Sci. USA 2019, 116, 11370-11379. [CrossRef]

18. Provencal, N.; Arloth, J.; Cattaneo, A.; Anacker, C.; Cattane, N.; Wiechmann, T.; Roh, S.; Kodel, M.; Klengel, T.; Czamara, D.; et al. Glucocorticoid exposure during hippocampal neurogenesis primes future stress response by inducing changes in DNA methylation. Proc. Natl. Acad. Sci. USA 2019. [CrossRef]

19. Wiench, M.; John, S.; Baek, S.; Johnson, T.A.; Sung, M.H.; Escobar, T.; Simmons, C.A.; Pearce, K.H.; Biddie, S.C.; Sabo, P.J.; et al. DNA methylation status predicts cell type-specific enhancer activity. EMBO J. 2011, 30, 3028-3039. [CrossRef]

20. Deschênes-Simard, X.; Gaumont-Leclerc, M.F.; Bourdeau, V.; Lessard, F.; Moiseeva, O.; Forest, V.; Igelmann, S.; Mallette, F.A.; Saba-El-Leil, M.K.; Meloche, S.; et al. Tumor suppressor activity of the ERK/MAPK pathway by promoting selective protein degradation. Genes Dev. 2013, 27, 900-915. [CrossRef]

21. Cristofalo, V.J. The effect of hydrocortisone on DNA synthesis and cell division during aging in vitro. Adv. Exp. Med. Biol. 1975, 53, 7-22. [CrossRef]

22. Mawal-Dewan, M.; Frisoni, L.; Cristofalo, V.J.; Sell, C. Extension of replicative lifespan in WI-38 human fibroblasts by dexamethasone treatment is accompanied by suppression of p21 Waf1/Cip1/Sdi1 levels. Exp. Cell Res. 2003, 285, 91-98. [CrossRef]

23. Xiao, D.; Dasgupta, C.; Chen, M.; Zhang, K.; Buchholz, J.; Xu, Z.; Zhang, L. Inhibition of DNA methylation reverses norepinephrine-induced cardiac hypertrophy in rats. Cardiovasc. Res. 2014, 101, 373-382. [CrossRef] [PubMed]

24. Xiong, F.; Xiao, D.; Zhang, L. Norepinephrine causes epigenetic repression of PKC $\varepsilon$ gene in rodent hearts by activating Nox1dependent reactive oxygen species production. FASEB J. 2012, 26, 2753-2763. [CrossRef]

25. Cristofalo, V.J.; Kabakjian, J. Lysosomal enzymes and aging in vitro: Subcellular enzyme distribution and effect of hydrocortisone on cell life-span. Mech. Ageing Dev. 1975, 4, 19-28. [CrossRef] 
26. Wust, S.; Federenko, I.S.; van Rossum, E.F.; Koper, J.W.; Hellhammer, D.H. Habituation of cortisol responses to repeated psychosocial stress-further characterization and impact of genetic factors. Psychoneuroendocrinology 2005, 30, 199-211. [CrossRef]

27. Bhake, R.C.; Leendertz, J.A.; Linthorst, A.C.; Lightman, S.L. Automated 24-hours sampling of subcutaneous tissue free cortisol in humans. J. Med. Eng. Technol. 2013, 37, 180-184. [CrossRef]

28. Tarjanyi, Z.; Montsko, G.; Kenyeres, P.; Marton, Z.; Hagendorn, R.; Gulyas, E.; Nemes, O.; Bajnok, L.; Gábor, L.K.; Mezosi, E. Free and total cortisol levels are useful prognostic markers in critically ill patients: A prospective observational study. Eur. J. Endocrinol. 2014, 171, 751-759. [CrossRef]

29. Hamrahian, A.H.; Oseni, T.S.; Arafah, B.M. Measurements of serum free cortisol in critically ill patients. N. Engl. J. Med. 2004, 350, 1629-1638. [CrossRef] [PubMed]

30. Christ-Crain, M.; Jutla, S.; Widmer, I.; Couppis, O.; Konig, C.; Pargger, H.; Puder, J.; Edwards, R.; Muller, B.; Grossman, A.B. Measurement of serum free cortisol shows discordant responsivity to stress and dynamic evaluation. J. Clin. Endocrinol. Metab. 2007, 92, 1729-1735. [CrossRef]

31. D’Anna, F.; Van Dyck, L.; Xiong, J.; Zhao, H.; Berrens, R.V.; Qian, J.; Bieniasz-Krzywiec, P.; Chandra, V.; Schoonjans, L.; Matthews, J.; et al. DNA methylation repels binding of hypoxia-inducible transcription factors to maintain tumor immunotolerance. Genome Biol. 2020, 21, 182. [CrossRef] [PubMed]

32. Starick, S.R.; Ibn-Salem, J.; Jurk, M.; Hernandez, C.; Love, M.I.; Chung, H.R.; Vingron, M.; Thomas-Chollier, M.; Meijsing, S.H. ChIP-exo signal associated with DNA-binding motifs provides insight into the genomic binding of the glucocorticoid receptor and cooperating transcription factors. Genome Res. 2015, 25, 825-835. [CrossRef] [PubMed]

33. Stavreva, D.A.; Wiench, M.; John, S.; Conway-Campbell, B.L.; McKenna, M.A.; Pooley, J.R.; Johnson, T.A.; Voss, T.C.; Lightman, S.L.; Hager, G.L. Ultradian hormone stimulation induces glucocorticoid receptor-mediated pulses of gene transcription. Nat. Cell Biol. 2009, 11, 1093-1102. [CrossRef]

34. Lee, R.S.; Tamashiro, K.L.; Yang, X.; Purcell, R.H.; Huo, Y.; Rongione, M.; Potash, J.B.; Wand, G.S. A measure of glucocorticoid load provided by DNA methylation of Fkbp5 in mice. Psychopharmacology 2011, 218, 303-312. [CrossRef]

35. Mehta, D.; Klengel, T.; Conneely, K.N.; Smith, A.K.; Altmann, A.; Pace, T.W.; Rex-Haffner, M.; Loeschner, A.; Gonik, M.; Mercer, K.B.; et al. Childhood maltreatment is associated with distinct genomic and epigenetic profiles in posttraumatic stress disorder. Proc. Natl. Acad. Sci. USA 2013, 110, 8302-8307. [CrossRef] [PubMed]

36. Cao-Lei, L.; Massart, R.; Suderman, M.J.; Machnes, Z.; Elgbeili, G.; Laplante, D.P.; Szyf, M.; King, S. DNA methylation signatures triggered by prenatal maternal stress exposure to a natural disaster: Project Ice Storm. PLoS ONE 2014, 9, e107653. [CrossRef] [PubMed]

37. Clark, S.J.; Argelaguet, R.; Kapourani, C.A.; Stubbs, T.M.; Lee, H.J.; Alda-Catalinas, C.; Krueger, F.; Sanguinetti, G.; Kelsey, G.; Marioni, J.C.; et al. scNMT-seq enables joint profiling of chromatin accessibility DNA methylation and transcription in single cells. Nat. Commun. 2018, 9, 781. [CrossRef]

38. Teschendorff, A.E. A comparison of epigenetic mitotic-like clocks for cancer risk prediction. Genome Med. 2020, 12, 56. [CrossRef] [PubMed]

39. Pidsley, R.; Zotenko, E.; Peters, T.J.; Lawrence, M.G.; Risbridger, G.P.; Molloy, P.; Van Djik, S.; Muhlhausler, B.; Stirzaker, C.; Clark, S.J. Critical evaluation of the Illumina MethylationEPIC BeadChip microarray for whole-genome DNA methylation profiling. Genome Biol. 2016, 17, 208. [CrossRef] [PubMed]

40. Chen, Y.A.; Lemire, M.; Choufani, S.; Butcher, D.T.; Grafodatskaya, D.; Zanke, B.W.; Gallinger, S.; Hudson, T.J.; Weksberg, R. Discovery of cross-reactive probes and polymorphic CpGs in the Illumina Infinium HumanMethylation450 microarray. Epigenetics 2013, 8, 203-209. [CrossRef]

41. Aryee, M.J.; Jaffe, A.E.; Corrada-Bravo, H.; Ladd-Acosta, C.; Feinberg, A.P.; Hansen, K.D.; Irizarry, R.A. Minfi: A flexible and comprehensive Bioconductor package for the analysis of Infinium DNA methylation microarrays. Bioinformatics 2014, 30, 1363-1369. [CrossRef]

42. Guintivano, J.; Shabalin, A.A.; Chan, R.F.; Rubinow, D.R.; Sullivan, P.F.; Meltzer-Brody, S.; Aberg, K.A.; van den Oord, E. Test-statistic inflation in methylome-wide association studies. Epigenetics 2020, 15, 1163-1166. [CrossRef]

43. Shabalin, A.A.; Hattab, M.W.; Clark, S.L.; Chan, R.F.; Kumar, G.; Aberg, K.A.; van den Oord, E. RaMWAS: Fast methylome-wide association study pipeline for enrichment platforms. Bioinformatics 2018, 34, 2283-2285. [CrossRef] [PubMed] 